\title{
THERMAL ANALYSIS OF SHELL AND TUBE HEAT EXCHANGER USING MAT LAB AND FLOEFD SOFTWARE
}

\author{
A.GopiChand ${ }^{1}$, A. V. N. L. Sharma ${ }^{2}$, G. Vijay Kumar ${ }^{3}$, A.Srividya ${ }^{4}$ \\ ${ }^{1}$ AssocProf, ${ }^{2}$ HOD,${ }^{3,4}$ STUDENT, MECHANICAL ENGINEERING, SWARNANDHRA COLLEGE OF ENGINEERING \\ AND TECHNOLOGY ANDHRA PRADESH, INDIA, allakagopichand@gmail.com, avnls277522@gmail.com \\ vijayramuk311@gmail.com, srividya330@gmail.com
}

\begin{abstract}
In this paper, a simplified model for the study of thermal analysis [1] of shell-and-tubes heat exchangers of water and oil type is proposed..Shell and Tube heat exchangers are having special importance in boilers, oil coolers, condensers, pre-heaters. They are also widely used in process applications as well as the refrigeration and air conditioning industry. The robustness and medium weighted shape of Shell and Tube heat exchangers make them well suited for high pressure operations. In this paper we have shown how to done the thermal analysis by using theoretical formulae for this we have chosen a practical problem of counter flow shell and tube heat exchanger of water and oil type, by using the data that come from theoretical formulae we have design[2] a model of shell and tube heat exchanger using Pro-e and done the thermal analysis by using Floefd software and comparing the result that obtained from Floefd software and theoretical formulae. For simplification of theoretical calculations we have also done a Matlab code which is useful for calculating the thermal analysis of a counter flow of water-oil type shell and tube heat exchanger.
\end{abstract}

Index Terms: Counter flow of shell and tube heat exchanger of oil and water type, Floefd software, Matlab software. $* * *$

\section{HEAT EXCHANGER}

A device whose primary purpose is the transfer of energy between two fluids is named a heat exchanger[4]. Aheat exchanger may be defined as an equipment which transfers the energy from a hot fluid to a cold fluid, with maximum rate and minimum investment and running costs[5].

\subsection{Shell and Tube Heat exchanger}

In this type of heat exchanger one of the fluids flow through a bundle of tubes enclosed by a shell. the outer fluid is forced through a shell and it flows over the outside surface of the tubes . such an arrangement is employed where reliability and heat transfer effectiveness[4]. It is the most common type of heat exchanger in oil refineries and other large chemical processes, and is suited for higher-pressure applications. This type of heat exchanger consists of a shell (a large pressure vessel) with a bundle of tubes inside it. One fluid runs through the tubes, and another fluid flows over the tubes (through the shell) to transfer heat between the two fluids

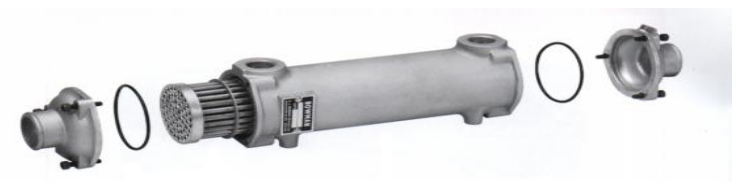

Fig-1:Shell and Tube Heat exchanger of type Water to oil .

\section{FLOEFD}

FloEFD can be used to study the fluid flow and heat transfer for a wide variety of engineering equipment. In this example we use FloEFD to determine the efficiency of a counter flow heat exchanger and to observe the temperature and flow patterns inside of it.

With FloEFD the determination of heat exchanger efficiency is straightforward and by investigating the flow and temperature patterns, the design engineer can gain insight into the physical processes involved thus giving guidance for improvements to the design.

A convenient measure of heat exchanger performance is its "efficiency" in transferring a given amount of heat from one fluid at higher temperature to another fluid at lower temperature. The efficiency can be determined if the temperatures at all flow openings are known. In FloEFD the temperatures at the fluid inlets are specified and the temperatures at the outlets can be easily determined.

\section{DESIGN CALCULATIONS [1]}

\subsection{THEORITICAL DESIGN CALCULATIONS:}

- $\quad m_{c}=$ Mass flow rate of cold fluid 
$m_{c}=0.9 \frac{\mathrm{kg}}{\mathrm{sec}}$

- $\quad m_{h}=$ Mass flow rate of hot fluid

$m_{h}=2.5 \frac{\mathrm{kg}}{\mathrm{sec}}$

- $\quad c p_{c}=$ Specific heat of cold fluid

$c p_{c}=4.2 \frac{\mathrm{kj}}{\mathrm{kg}^{o} \mathrm{k}}$

- $\quad c p_{h}=$ Specific heat of hot fluid

$$
c p_{h}=2.5 \frac{\mathrm{kj}}{\mathrm{kg}^{o} \mathrm{k}}
$$

- $\quad T_{h i}=$ Inlet temperature of hot fluid

$T_{h i}=383^{\circ} \mathrm{k}$

- $T_{h 2}=$ Outlet temperature of hot fluid

$T_{h 2}=360^{\circ} \mathrm{k}$

- $T_{c 1}=$ Inlet temperature of cold fluid

$T_{c 1}=308^{\circ} k$

- $\quad T_{c 2}=$ Outlet temperature of cold fluid

- $\rho=$ Density of oil

$$
\rho=850 \frac{\mathrm{kg}}{\mathrm{m}^{3}}
$$

- $U_{o}=$ Overall heat transfer coefficient

- $\quad \Sigma=$ Effectiveness of heat exchanger

$$
U_{o}=350 \frac{w}{m^{2 o} k}
$$

- $\Delta T_{l m}=$ Logarithmic mean temperature difference

- $Q=$ Total heat transfer

$$
Q=m_{c} c_{c} \Delta T_{l m}
$$

$\mathrm{Q}=$ heat gain by the cold liquid=heat loss by the hot liquid

$$
\begin{gathered}
Q=m_{c} c_{c} \Delta T_{l m}=m_{h} c_{h} \Delta T_{l m} \\
0.9 \times 4.2 \times\left(T_{c 2}-308\right)=2.5 \times 2.5 \times(383-360) \\
=346.029 \mathrm{k}
\end{gathered}
$$

- $\quad$ Outlet temperature of cold liquid

$$
\begin{aligned}
& T_{c 2}=346^{\circ} \mathrm{k} \\
& \begin{aligned}
Q & =m_{c} c_{c} \Delta T_{l m} \\
& =0.9 \times 4.2 \times(346-308) \\
& =143.74 \mathrm{kw}
\end{aligned}
\end{aligned}
$$

- Rate of heat transfer $Q=143.74 k w$

- Logarithmic mean temperature distribution for counter flow heat exchanger(LMTD)

$$
\begin{gathered}
\Delta T_{l m}=\frac{\Delta T_{1}-\Delta T_{2}}{\ln \left(\Delta T_{1} / \Delta T_{2}\right)} \\
\Delta T_{1}=T_{h 1}-T_{c 2} \\
\Delta T_{2}=T_{h 2}-T_{c 1} \\
=\frac{(383-346)-(360-308)}{\ln \left({ }^{(383-346) /(360-308)}\right)} \\
=44.07^{\circ} \mathrm{k}
\end{gathered}
$$

$$
\begin{gathered}
A=\frac{Q}{U_{0} \Delta T_{l m}} \\
A=\frac{143.74 \times 10^{3}}{350 \times 44} \\
A=9.318 m^{2}
\end{gathered}
$$

- Area of tube

$$
\begin{aligned}
& A_{t}=\frac{m_{h}}{\rho v} \\
& =\frac{2.5}{850 \times 0.35}=0.0084 \mathrm{~m}^{2} \\
& A_{t}=0.0084 \mathrm{~m}^{2}
\end{aligned}
$$

- Number of tubes

$$
\begin{aligned}
& A_{t}=n \Pi \frac{d^{2}}{4}=\frac{0.0084 \times 4}{\Pi\left(0.02^{2}\right)} \\
& n=\frac{A_{t} \times 4}{\Pi d^{2}} \quad n=26.93=27 \text { tubes }
\end{aligned}
$$


- Length of tubes

$$
\begin{aligned}
A & =n \prod d L \\
L & =\frac{9.318}{27 \times \prod \times 0.02} \\
L & =5.49 m
\end{aligned}
$$

- Shell outer diameter

$$
\begin{aligned}
& D_{O}=\frac{A}{\prod L} \\
& =\frac{9.318}{\Pi \times 5.49}=0.540 \mathrm{~m} \\
& D_{o}=0.540 \mathrm{~m}
\end{aligned}
$$

- Effectiveness

$$
\begin{aligned}
& \Sigma=\frac{C_{\max }\left(T_{h 1}-T_{h 2}\right)}{C_{\min }\left(T_{h 1}-T_{c 1}\right)} \\
& C_{\max }=\max \text { of } C_{h} \text { or } C c \\
& C_{\min }=\min \text { of } C_{h} \text { or } C c \\
& C_{\min }=C c=m_{c} C p_{c}=0.9 \times 4.2=3.78 \\
& C_{\max }=C_{h}=m_{h} C p_{h}=2.5 \times 2.5=6.25 \\
& =\frac{C c\left(T_{h 1}-T_{c 2}\right)}{C h\left(T_{h 1}-T_{c 1}\right)} \\
& =\frac{6.25(383-360)}{3.78(383-308)}=0.507050 \\
& \sum=0.507050
\end{aligned}
$$

\subsection{THERMAL ANALYSIS CALCULATIONS BY}

\section{USING MATLAB.}

For thermal analysis calculations by using Matlab program we have to provide some parameters like mass flow rate of hot liquid and cold liquid. Temperatures of inlet and outlet of hot liquid and inlet temperature of cold liquid.

\section{Input}

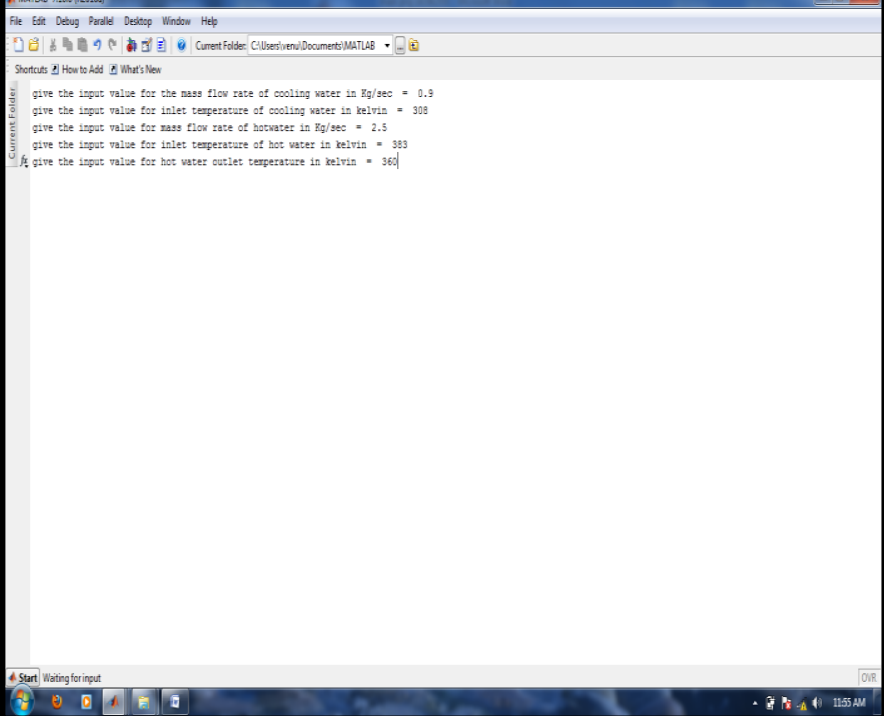

\section{Output}

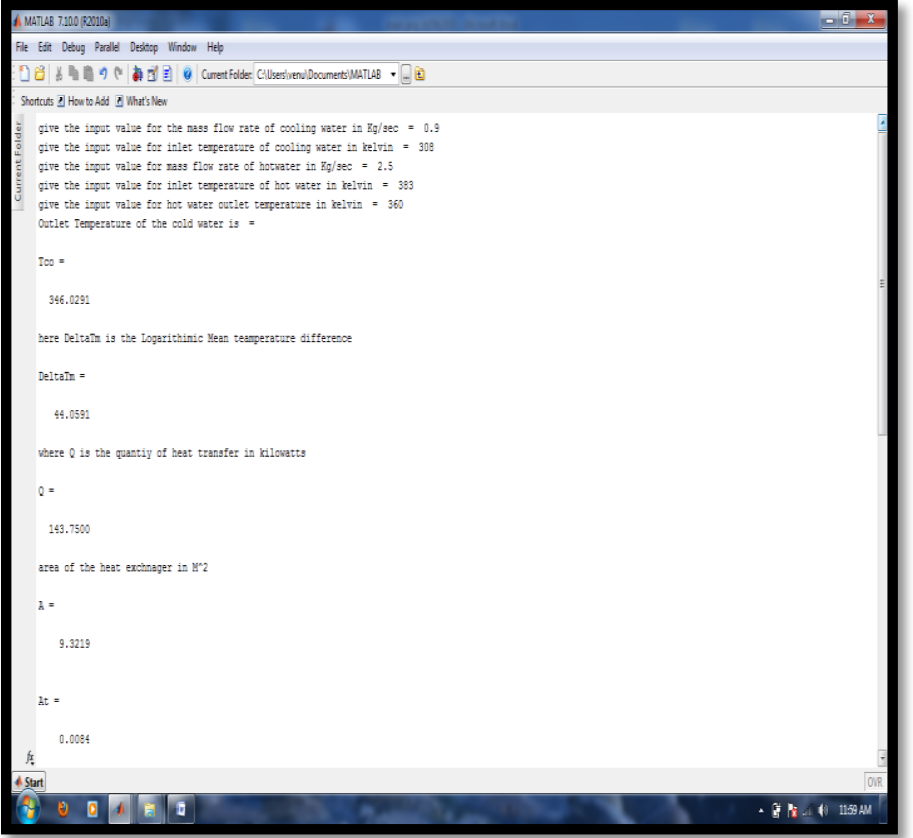




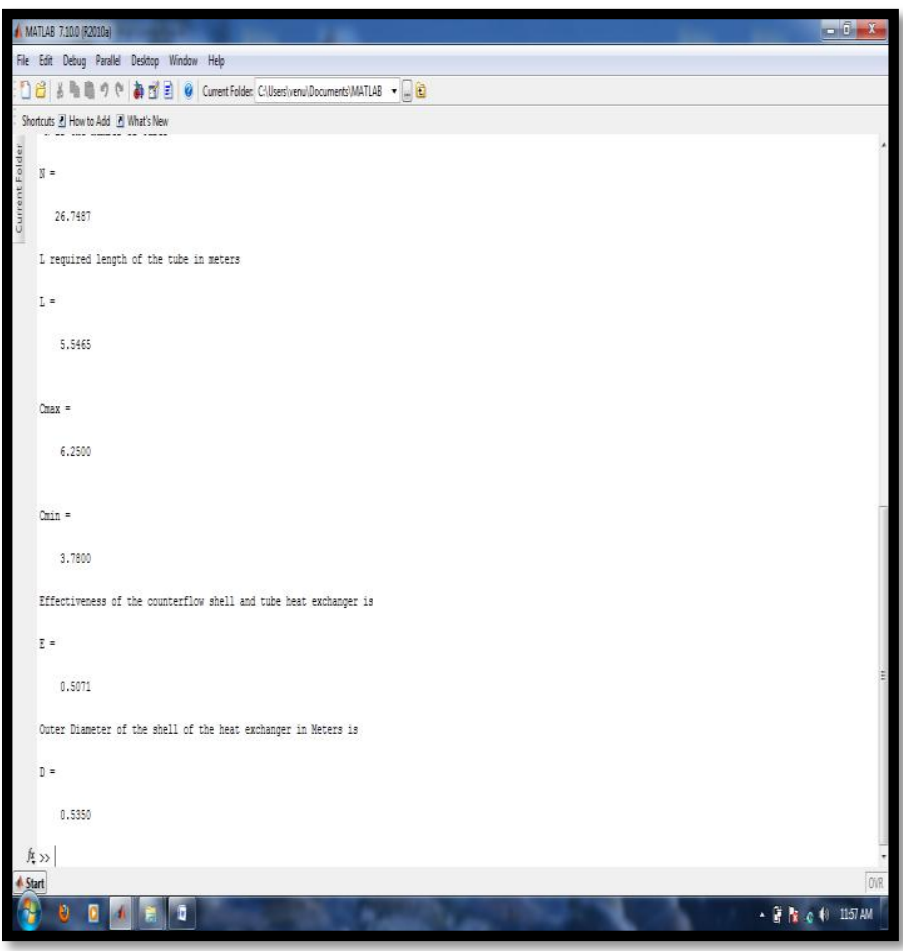

\section{MODELING OF SHELL AND TUBE}

\section{HEATEXCHNAGER USING PRO-E}

\section{SHELL}

Outer diameter of the shell is $540 \mathrm{~mm}$

Inner diameter of the shell is $520 \mathrm{~mm}$

Thickness of the shell is $10 \mathrm{~mm}$

Material we have taken for shell is stainless steel

Length of the shell $5.49 \mathrm{~m}$

Inlet and outlet nozzle diameter of the shell is $100 \mathrm{~mm}$

Thickness is $10 \mathrm{~mm}$

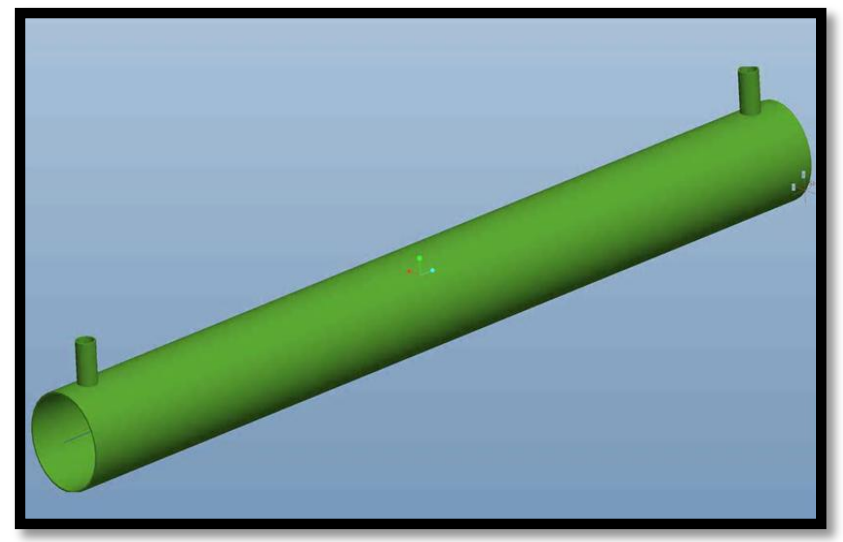

Fig 2 SHELL

\section{FLANGE}

Outer Diameter of the flange is $540 \mathrm{~mm}$ Inner Diameter of the flange is $520 \mathrm{~mm}$ Thickness is $10 \mathrm{~mm}$

Outer diameter of the nozzle is $100 \mathrm{~mm}$ Inner diameter of the nozzle is $80 \mathrm{~mm}$

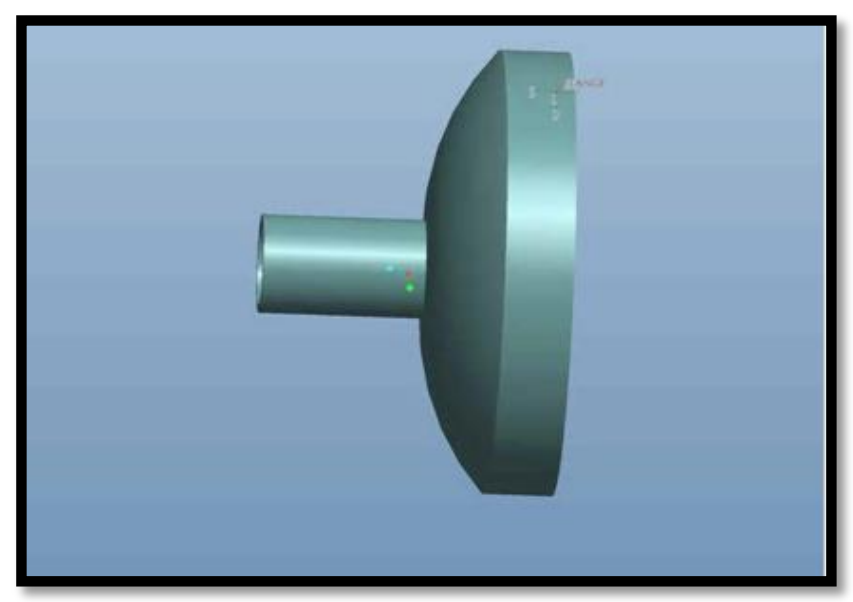

Fig 3: FLANGE

\section{BAFFLE END PLATE}

Diameter of the baffle end plate is $520 \mathrm{~mm}$ Number of holes on the baffle end plate is 28 Hole diameter is $20 \mathrm{~mm}$

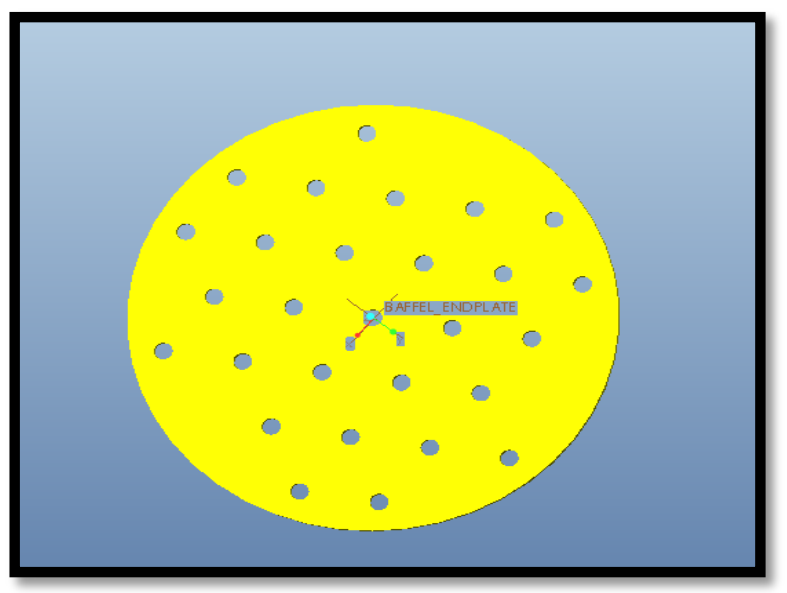

Figure 4. BAFFLE END PLATE

\section{BAFFLE PLATE}

Baffle cut is $25 \%$

Thickness of the baffle plate is $10 \mathrm{~mm}$ 


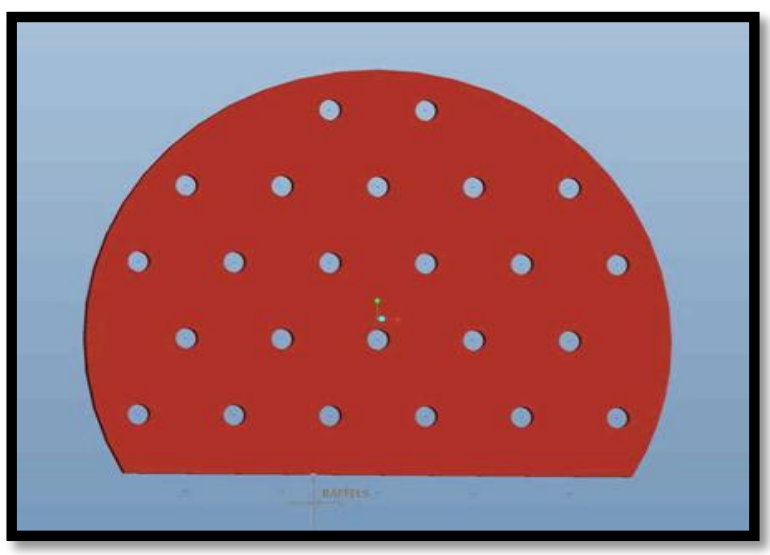

Fig 5:- BAFFLE PLATE

\section{TUBE}

Outer diameter of the tube is $20 \mathrm{~mm}$

Inner diameter of the tube is $16.4 \mathrm{~mm}$

Length of the tube is $5.49 \mathrm{~m}$

Number of the tubes is 28

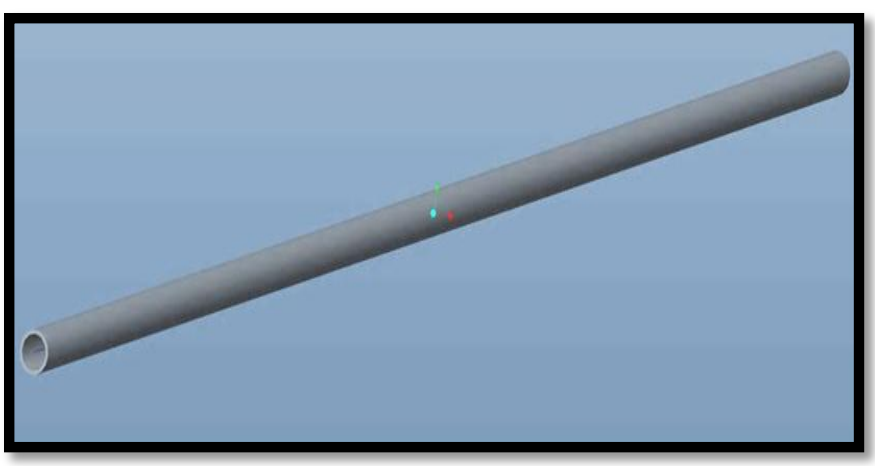

Fig 6:TUBE

\section{PRO-E Assembly Model}

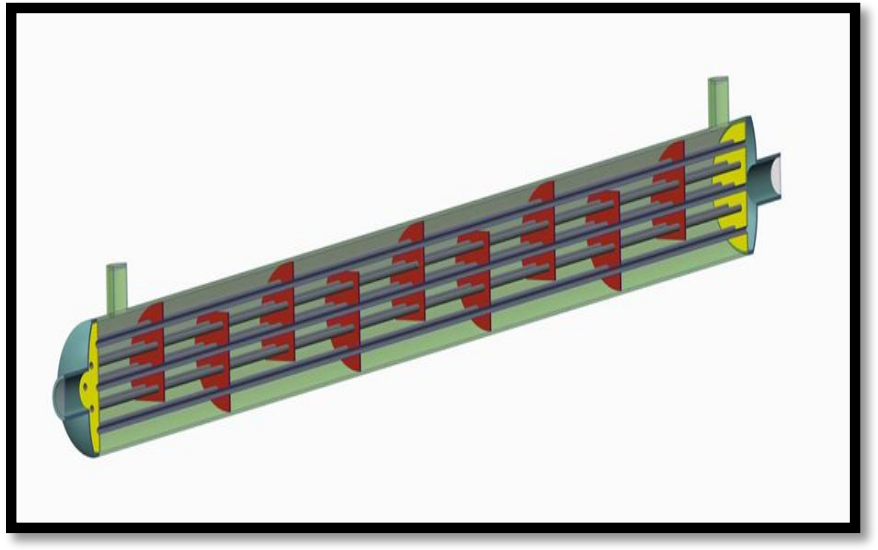

Fig 7: Model of shell and tube heat exchanger

\section{THERMAL ANALYSIS USING FLOEFD}

By using the thermal analysis result that obtained from theoretical formulae. We have designed a Pro-e Model, and the materials we used for thermal analysis for tubes is copper and shell is stainless steel because Copper is one of the best conductors of heat, while stainless steel is a mediocre conductor. Using copper would increase the rate at which heat was transferred from oil to the water which is imported into the FLOEFD software and started the analysis, the results that obtained from FLOEFD where represented by contour plots.

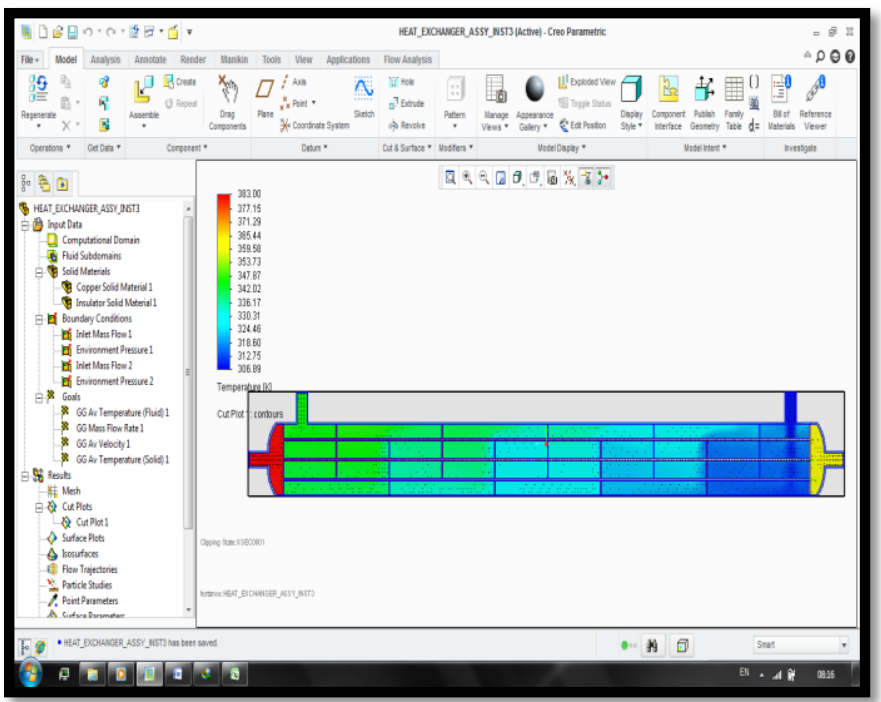

Figure 5.1:Contour Plot Results of Temperatures of Inlet and Outlet temperatures of Hot and cold liquids.

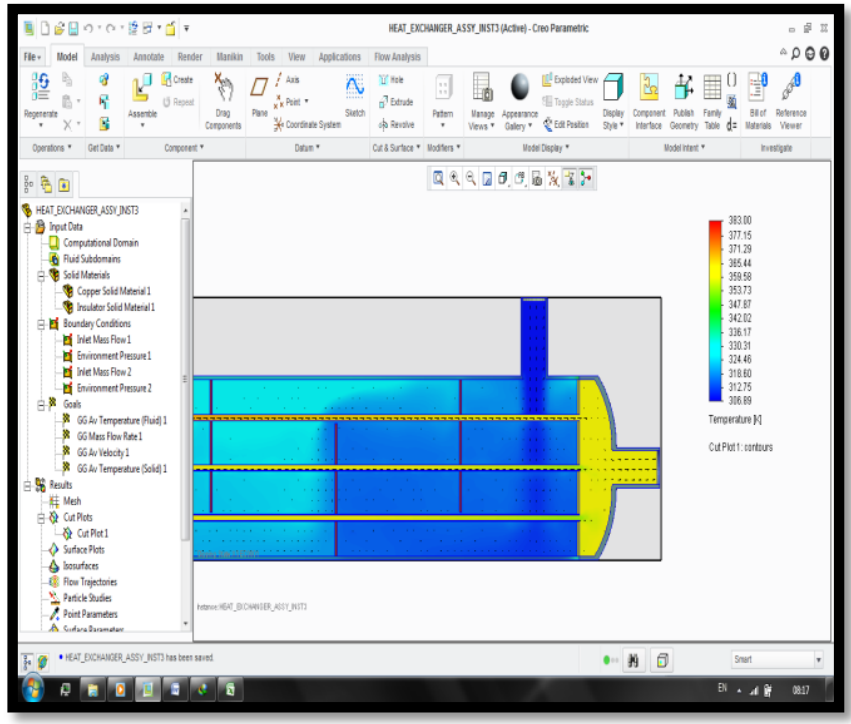

Figure 5.2:-Halfcutted Contour Plot results that showing the temperature of Outlet Hot oil(Yellow color) and Inlet Temperature of cold water(Blue color). 


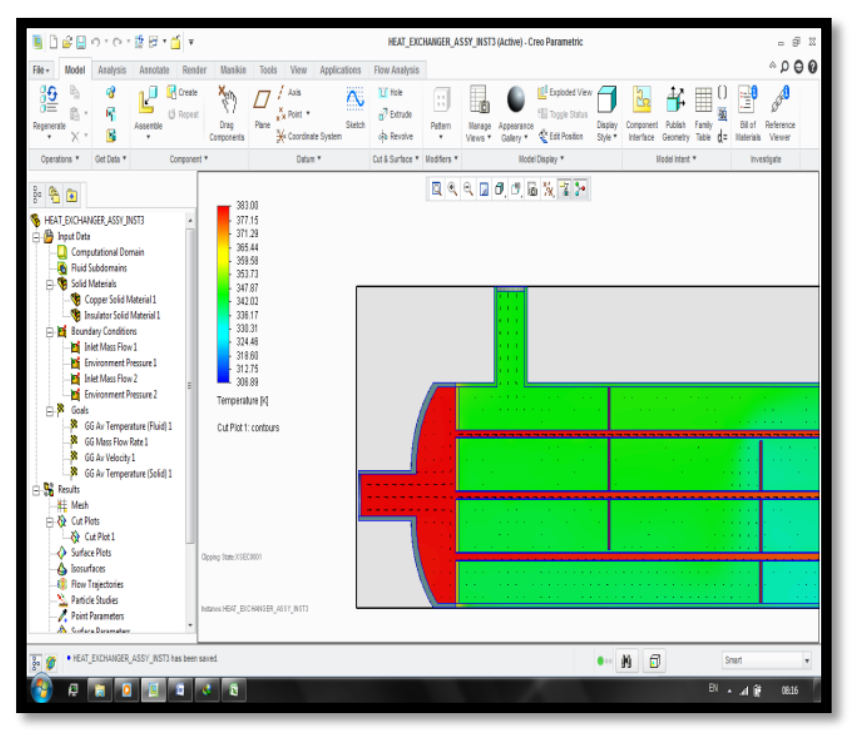

Figure 5.3: Half cutted Contour plot results that showing the temperatures of Inlet Hot Oil(red colour)and outlet temperature of cold water(greenish colour).

\section{CONCLUSIONS}

We have done the thermal analysis of water to oil type of shell and tube heat exchanger using Matlab and by using the output that come from Matlab we have modeled a shell and tube heat exchanger using Pro-e and imported this model in Floefd software and we have run the thermal analysis and we compared the both results and we are getting an error of 0.02 3in effectiveness .By using above process we can do the thermal analysis in less time and our analysis report also most accurate .

\section{ACKNOWLEDGEMENTS}

We thanks to our Assoc.Prof.R.Samsukumar for providing Necessary support doing this work. we acknowledge the diligent efforts of Ramgopal Varma Dandu,Applicant Engineer,Trident Tech Lab for doing thermal Anaylsis.

\section{REFERENCES}

[1]International Journal of Ambient Energy, Volume 31, Number 4Thermal analysis of counterflow heat exchanger with a heat source Assad, Kotiaho

[2].http://www.copper.org/applications/rodbar/alloy360/cu_ste el.html

[3]. MNL 032A Issued 29 August 08, Prepared by J.E.Edwards of $P$ \& I Design Ltd, Teesside, UK www.pidesign.co.uk

[4]Shah, R. K. and Seculik, D. P. Fundamentals of Heat Exchanger Design. Wiley: New York, 2003 .

[5].Fundamentals of Engineering Heat and mass transfer by R.C.Sachdva 